\title{
Substitution of non-forage fibre sources for cereal grains and molasses in calf starter on performance and development of ruminal function
}

\author{
D.B. Vagnoni ${ }^{1 *}$, C. Sousa ${ }^{1}$ and M.A. Messman ${ }^{2}$ \\ ${ }^{1}$ Department of Animal Science, California Polytechnic State University, 1 Grand Ave, San Luis Obispo, CA 93407, USA; \\ ${ }^{2}$ Cargill Animal Nutrition Center, 10383 165 th Ave NW, Elk River, MN 55330,USA; dvagnoni@calpoly.edu
}

Received: 16 September 2020 / Accepted: 14 December 2020

(c) 2021 D.B. Vagnoni et al.

RESEARCH ARTICLE

CALVES

\begin{abstract}
One hundred and thirty-six, new-born female Holstein calves (body weight $(B W)=37.6 \pm 0.79 \mathrm{~kg}$ ) were allocated to one of four starter feeds to evaluate the effects of replacing cereal grains and (or) molasses with non-forage fibre sources on intake, weight gain, and indicators of ruminal development. Diets consisted of a typical, low (16\%) neutral detergent fibre (NDF) texturised calf starter, texturised calf starter with moderately higher (20\%) NDF, texturised calf starter with moderately higher (21\%) NDF and no molasses, and a complete pelleted high (25\%) NDF calf starter. Average daily gains and starter intakes were unaffected by moderate levels of NDF. Average daily gain and feed intakes were increased in the preweaning phase but decreased in the postweaning phase by the high NDF complete pelleted diet. Total tract apparent NDF digestibility increased linearly with age but did not differ among diets. Blood concentrations of glucose and $\beta$-hydroxybutyrate (BHB) decreased and increased, respectively, with age. Further, blood BHB concentrations were largely unaffected by diet and did not change with increasing dry matter (DM) intake until a threshold was reached, and then increased linearly. Calf-side blood BHB testing resulted in an appreciable number of measurements below the limit of detection of the meter, resulting in censored data. Application of appropriate statistical methodology, required for proper parameter estimation from censored data, suggest the potential for successful field application of calf-side BHB measurements for monitoring starter intake and readiness for weaning in commercial settings. Feeding solely a complete pelleted calf starter throughout the starter phase may provide insufficient levels of effective fibre. Integration of the results of this study with previously published literature via a quantitative analysis suggests that maintaining intake may be the key to successful inclusion of non-forage fibre sources in calf starters.
\end{abstract}

Keywords: $\beta$-hydroxybutyrate, calf starter, non-forage fibre sources

\section{Introduction}

New-born calves are effectively non-ruminants who initially obtain blood glucose and amino acids from small intestinal digestion and absorption of milk lactose and protein, respectively. Profound changes in the provision of these substrates occur with growth, development, and increasing dry feed intake. Blood glucose is increasingly supplied by ruminally absorbed propionic acid resulting from carbohydrate fermentation, while the major source of amino acids transitions to ruminally synthesised microbial crude protein $(\mathrm{CP})$. These changes in nutrient provision entail the establishment of the characteristic ruminal microflora and fermentative digestion and also the development of the requisite ruminal capacity, musculature and epithelial function (Baldwin et al., 2004). Post-absorption, this requires the development of hepatic gluconeogenic capacity and the transition from glucose to acetate as the primary energyyielding substrate by peripheral tissues (Bergman, 1990). In addition to these developmental processes, adequate growth must be maintained to facilitate sufficiently rapid entry into the milking herd. Both the chemical composition 
of dietary carbohydrates (e.g. sugars, starch, fibre) and the physical form of the diet have important implications for both this transition to a functional ruminant and also the growth performance of young calves.

Texturised starter feeds are commonly fed to calves due to their chemical composition and physical form. Because of their high cereal grain (and thus high starch) content, they provide a relatively high level of digestible energy (DE), important for supporting adequate growth (Hu et al., 2018) and high ruminal concentrations of butyric and propionic acids, which promote ruminal papillae development (Sakata and Tamate, 1978, 1979; Sander et al., 1959; Stobo et al., 1966). Cereal grains are incorporated in a coarse form in an effort to provide adequate abrasiveness (Greenwood et al., 1997) important for maintaining gut health by reducing abnormalities such as plaque formation, acidosis and parakeratosis (Khan et al., 2016). Liquid molasses is included in texturised feeds to reduce particulate fines and reputedly enhance palatability (Hill et al., 2008a) and also for its potential to stimulate ruminal development by increasing ruminal butyrate (Martel et al., 2011; Oltramari et al., 2016).

Provision of unground forage to calves promotes normal development of rumen tissue (Khan et al., 2016) but may limit intake due to the accumulation of undigested residues (Drackley, 2008). Relative to forages, non-forage fibre sources (NFFS), such as wheat middlings, soy hulls or distillers grains, generally have high extents and similar rates of ruminal neutral detergent fibre (NDF) digestion (NDFD) and higher passage rates out of the rumen in mature cows (Firkins, 1997). Thus, although they lack the bulky and abrasive characteristics of forages, substituting NFFS for some cereal grains may allow for adequate voluntary intake and DE to maintain adequate growth rate. At the same time, this may mitigate some of the negative effects associated with high grain feeding in young calves, such as reduced NDFD (Hill et al., 2016; Quigley et al., 2018) and the risk of ruminal acidosis and can reduce the cost of the starter feed.

Previous studies with substituting NFFS for cereal grains have reported reductions in average daily gain (ADG) or intake (Dennis et al., 2017; Fokkink et al., 2011; Hill et al., 2012, 2016), but starter feed NDF content was increased to more than $20 \%$ in each of these instances. SuarezMena et al. (2011) ran a series of trials involving a variety of inclusion levels of distillers grains and likewise found reduced ADG and feed efficiency at high inclusion levels, but no reductions in ADG or intake when dietary NDF was increased by $5 \%$ or less. These results suggested that there is potential for the successful inclusion of moderate amounts of NFFS in calf starters. Thus, the objective of the following study was to evaluate the effects of substituting moderate amounts of NFFS (primarily as wheat middlings) for cereal grains and molasses on performance, fibre digestibility, and blood parameters of young calves.

\section{Materials and methods}

New-born Holstein heifer calves $(n=136)$ were received at a commercial calf rearing facility in Tulare, CA, USA from local dairy farms over six consecutive days. Colostrum was administered at the farm of origin before pick-up, hence quantity and timing of colostrum offered was not controlled. Upon arrival, calves were weighed on a digital platform scale capable of reading weights to the nearest 0.1 $\mathrm{kg}$ and a jugular blood sample collected by venipuncture. Serum was separated by centrifugation $(3,000 \times g$ for 10 min at room temperature) and serum total protein was estimated using an optical refractometer (Sper Scientific, Scottsdale, AZ, USA).

Calves were balanced by initial body weight (BW; $37.6 \pm 0.79$ $\mathrm{kg} ; 34$ per treatment) and farm of origin, and assigned to one of four commercially available starter feeds (Table 1) to evaluate the effects of substituting NFFS, primarily from wheat middlings, for cereal grains and molasses. Three diets were offered as texturised diets, whereby steam flaked corn and barley, cane molasses, and additives were combined with the remainder of the ingredients which had been ground through a $2 \mathrm{~mm}$ screen and then pelleted $(3 \times 10 \mathrm{~mm})$. The control diet $(\mathrm{CTRL})$ consisted of a typical low fibre, high starch formulation. This diet was modified by replacing a portion of the cereal grain with a moderate amount of fibre from NFFS (MFIB). Diet MFIB was then modified by replacing the liquid molasses with a further amount of NFFS (MFIBNM). The final diet (HFPEL) consisted of a complete pellet that contained a further increase in wheat middlings and without steam flaked corn, barley, or liquid molasses. The increased NDF content relative to diet CTRL was 4-5\% for diets MFIB and MFIBNM and $9 \%$ for diet HFPEL.

Calves were housed in individual wooden hutches $(0.81 \times 1.52 \mathrm{~m})$ and offered water and starter feed ad libitum throughout the study. There was no long fibre offered for consumption and there was also no bedding in the hutches. Feed offered and refused was measured daily and fresh water was added at least once daily. Pasteurised waste milk, received from local dairies, was offered at the rate of $3.8 \mathrm{l} / \mathrm{d}$ in two equal morning and evening feedings until $42 \mathrm{~d}$ of age. Milk provision was restricted to morning feeding only (i.e. 1.9 l) from 43-49 d of age, at which point calves were weaned. Calf BW was measured again at 49 and $70 \mathrm{~d}$ of age. All procedures were approved by the California Polytechnic State University Animal Care and Use Committee.

Samples of starter feed were obtained weekly and faecal samples were obtained by rectal stimulation at 3, 6, and 9 weeks of age. Samples of pasteurised milk were obtained 
Table 1. Ingredient and nutrient composition of experimental diets. ${ }^{1}$

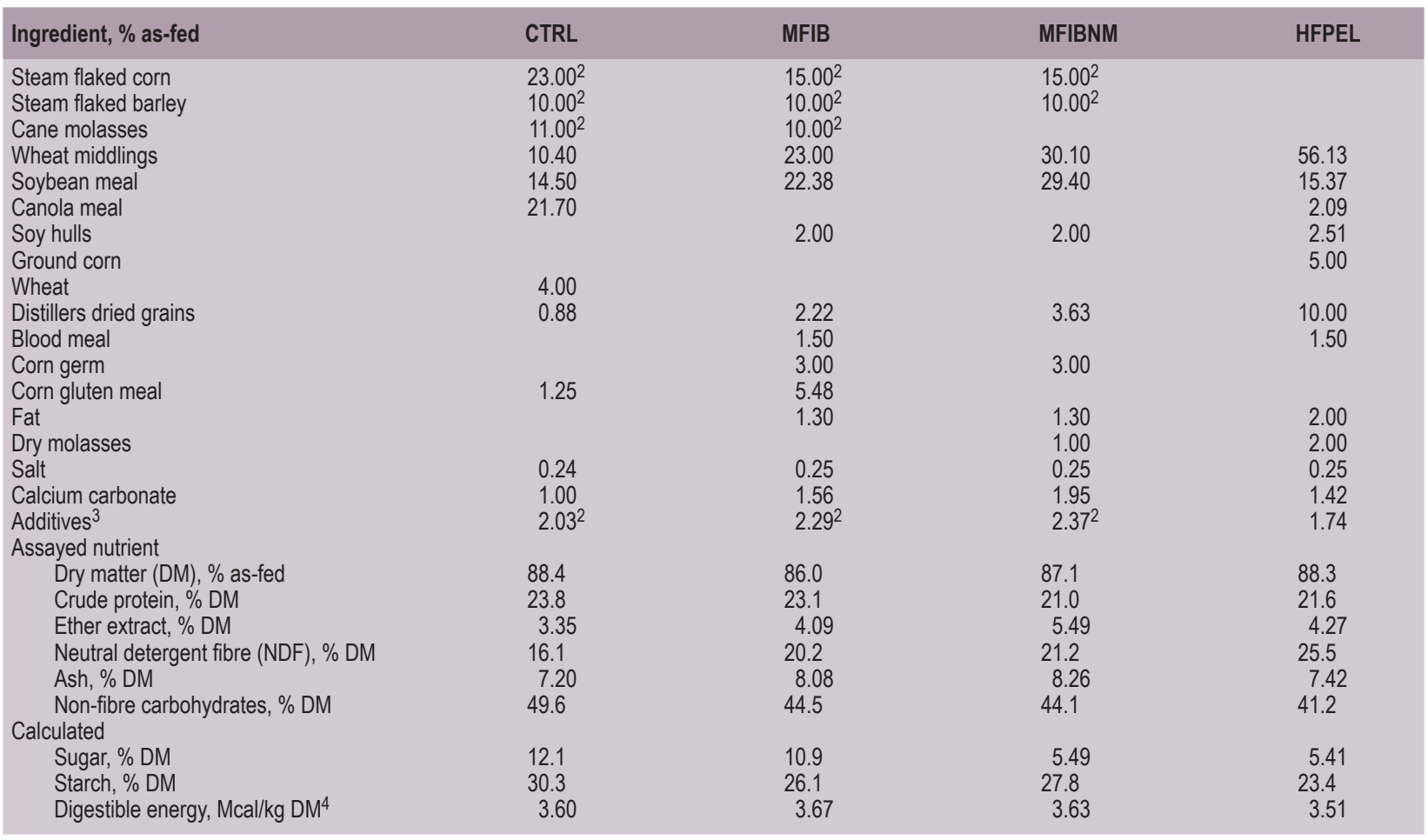

${ }^{1}$ Diet $\mathrm{CTRL}$ = typical low NDF texturised starter; MFIB = moderate fibre texturised; MFIBNM = moderate fibre, no liquid molasses texturised; HFPEL = high fibre pelleted starter.

${ }^{2}$ These ingredients were blended into the pelleted portion of these diets, which consisted of the remaining ingredients in each diet.

${ }^{3}$ Contained flow agent, trace minerals and vitamins, flavour, preservative, and Bovatec (lasalocid sodium) at $66 \mathrm{mg} / \mathrm{kg}$ Zoetis, Parsippany, NJ, USA).

${ }^{4}$ NRC, 2001.

and stored by farm personnel but were lost during storage and were unavailable for analyses. Jugular blood samples were obtained by venipuncture at $4,6,8$, and 10 weeks of age using an 18-gauge needle attached to a $5 \mathrm{ml}$ syringe. Glucose and $\beta$-hydroxybutyrate (BHB) concentrations were measured immediately using test strips (Nova Max Plus meter, Nova Biomedical Corporation, Waltham, MA, USA) whereby a drop of whole blood was placed on the test strip inserted into the meter. Following collection, feed samples were stored at $-20^{\circ} \mathrm{C}$ while faecal samples were immediately dried for $72 \mathrm{~h}$ (with periodic turning) at $55^{\circ} \mathrm{C}$ prior to storage.

After completion of the trial, faecal samples were ground (1-mm screen, Wiley mill, Arthur A. Thomas Co., Philadelphia, PA, USA) and then dried $\left(24 \mathrm{~h}\right.$ at $\left.105^{\circ} \mathrm{C}\right)$ for DM determination while feed samples were dried $(24 \mathrm{~h}$ at $105^{\circ} \mathrm{C}$ ) and then ground. All samples were assayed for ash (method 942.05; AOAC, 1990) and acid insoluble ash (Van Keulen and Young, 1977). Feed samples were additionally analysed for CP (with an Elementar Rapid N Exceed) and crude fat (Ankom XT 15, Macedon, NY, USA), and both feed and faecal samples were assayed for NDF (Ankom 2000) with ash, including sodium sulphite and heat-stable amylase (Van Soest et al., 1991).
Daily mean starter DM intake (DMI) was computed by week and by feeding phase (pre- and post-weaning) and total DMI by phase. Body weight gain was computed as average daily values and totals by phase. Feed efficiency in the post-weaning phase was computed as the ratio of total BW gain to total starter DMI. Total tract apparent NDF digestibility (NDFD) was calculated from the ratio of acid insoluble ash to NDF in the starter feed and faeces.

Statistical analyses were conducting using $\mathrm{R}$ version 3.6.0 ( $\mathrm{R}$ Core Team, 2019). When repeated measurements were made (i.e. final BW, BW gain, ADG, starter intake, NDFD, blood glucose), data were analysed using a mixed-effects model using the nlme package that included the fixed effects of diet, time (i.e. phase or week of age), and their interaction and also the random effect of calf within dairy. When phase constituted the repeated time of measurement (i.e. only two categorical levels, pre- and post-weaning), heteroscedasity was modelled using the varIdent function, appropriate for nominal data, and correlations among errors were modelled using a compound symmetry structure (Pinheiro and Bates, 2000). When the repeated unit of time was week of age (i.e. several levels of numeric data), heteroscedasity was modelled using the varPower function where fitted values were offered as the variance covariate. 
This function accommodates cases where the variance either increases or decreases with the covariate (Pinheiro and Bates, 2000). In these cases, correlation among errors was modelled using autoregressive order $=1$ variancecovariance structure, more generally applicable for time series data, where correlations between observations are expected to decrease with their distance (Pinheiro and Bates, 2000). In all cases, plots of standardised residuals were inspected to confirm that residuals were reasonably centred at zero, constant and normally distributed.

Due to the presence of non-detects in the blood BHB measurements (i.e. blood BHB values below $0.1 \mathrm{mmol} / \mathrm{l}$, the limit of detection of the meter), the statistical analyses were adapted. These data were analysed at each individual sampling time, using maximum likelihood estimations (MLE) appropriate for left-censored data, which are widely applied in environmental sciences (Helsel, 2012). This approach uses the numerical values above the detection limit, the proportion of data below the detection limit, and an assumed distribution of data to estimate parameters (e.g. means and SE) which allowed for hypothesis testing similar to analysis of variance. Based on probability plots, a lognormal distribution of the data was selected. Data analyses were implemented using the cenlme function from the NADA package; dietary contrasts of interest were performed at each time point on the transformed data and means and SE for the original data scale were then backcalculated (Gilbert, 1987) for presentation.

Data for serum total protein and initial BW, which were measured only once, were analysed using ANOVA with treatment as a fixed effect. Diet mean separations were accomplished using pre-planned single degree of freedom contrasts to evaluate the effects of a moderate replacement of cereal grain with NFFS (CTRL vs MFIB), further replacement of liquid molasses with NFFS (MFIB vs MFIBNM) and the effect of a complete pelleted high NFFS diet (HFPEL vs CTRL). The effects of time (either week or phase) and interactions with dietary contrasts were of primary interest. Finally, post-hoc single df contrasts were occasionally constructed to evaluate specific effects of diets and time based on observed data.

\section{Results and discussion}

Diets were formulated for $21.5 \% \mathrm{CP}$ and observed dietary CP content (Table 1) ranged from 21.0-23.8\% of DM. These were all above the required concentrations for calves of this age (Hill et al., 2013), and so should not been limiting in this experiment. Dietary NDF content (as \% of DM) increased progressively from the control diet through the moderate fibre diets to the high fibre diet as expected. A greater separation was expected between diets MFIB and MFIBNM and it is difficult to explain why this was not observed. Neither initial serum total protein nor BW (Table 2) differed due to any dietary contrasts of interest $(P \geq 0.49)$ or had an effect on weight gains when evaluated as covariates $(P \geq 0.24)$, indicating that dietary comparisons were unaffected by these variables, and so were excluded from further consideration.

Body weights and weight gains, starter DMI and feed efficiency were unaffected by a moderate increase in NFFS

Table 2. Least square means for initial serum total protein and body weight (BW) and performance of Holstein heifer calves fed starter diets $^{1}$ differing in carbohydrate content and physical form during the preweaning (49 d) and postweaning (21 d) phases of growth.

\begin{tabular}{|c|c|c|c|c|c|c|c|c|c|c|c|c|}
\hline \multirow[t]{2}{*}{ Item } & \multicolumn{5}{|l|}{ Diet } & \multirow{2}{*}{$\frac{P \text {-value }}{\text { Phase }}$} & \multicolumn{3}{|c|}{$P$-value, Contrast ${ }^{2}$ Effect } & \multicolumn{3}{|c|}{$P$-value, Contrast ${ }^{2} \times$ Phase } \\
\hline & CTRL & MFIB & MFIBNM & HFPEL & SEM & & MF & MOL & HFP & MF & MOL & HFP \\
\hline Serum total protein, g/dl & 5.39 & 5.59 & 5.47 & 5.50 & 0.20 & - & 0.49 & 0.68 & 0.68 & - & - & - \\
\hline Initial BW, kg & 37.4 & 39.4 & 37.6 & 37.9 & 1.22 & - & 0.24 & 0.30 & 0.77 & - & - & - \\
\hline Final BW, kg & & & & & 1.3 & $<0.001$ & 0.70 & 0.07 & 0.55 & 0.31 & 0.22 & 0.017 \\
\hline Preweaning & 63.9 & 63.9 & 66.2 & 64.5 & - & - & - & - & - & - & - & - \\
\hline Postweaning & 81.6 & 80.2 & 84.3 & 78.9 & - & - & - & - & - & - & - & - \\
\hline BW gain, $\mathrm{kg}$ & & & & & 1.02 & $<0.001$ & 0.74 & 0.05 & 0.31 & 0.30 & 0.81 & 0.022 \\
\hline Preweaning & 25.5 & 26.3 & 28.6 & 26.9 & - & - & - & - & - & - & - & - \\
\hline Postweaning & 17.7 & 16.3 & 18.1 & 14.4 & - & - & - & - & - & - & - & - \\
\hline Average daily gain, $\mathrm{kg}$ & & & & & & $<0.001$ & 0.59 & 0.17 & 0.041 & 0.58 & 0.89 & 0.016 \\
\hline Preweaning & 0.536 & 0.536 & 0.583 & 0.548 & 0.023 & - & - & - & - & - & - & - \\
\hline Postweaning & 0.844 & 0.804 & 0.862 & 0.684 & 0.046 & - & - & - & - & - & - & - \\
\hline Starter dry matter intake & & & & - & $<0.001$ & 0.99 & 0.35 & 0.97 & 0.87 & 0.99 & 0.068 & \\
\hline Preweaning & 0.346 & 0.354 & 0.412 & 0.425 & 0.023 & - & - & - & - & - & - & - \\
\hline Postweaning & 2.03 & 2.03 & 2.09 & 1.96 & 0.070 & - & - & - & - & - & - & - \\
\hline Total starter DMI, kg & & & & 1.3 & $<0.001$ & 0.92 & 0.23 & 0.46 & 0.81 & 0.36 & 0.0022 & \\
\hline Preweaning & 17.0 & 17.4 & 20.2 & 20.9 & - & - & - & - & - & - & - & - \\
\hline Postweaning & 42.6 & 42.6 & 43.8 & 41.2 & - & - & - & - & - & - & - & - \\
\hline Gain:feed, postweaning & 0.42 & 0.40 & 0.41 & 0.36 & 0.026 & - & 0.42 & 0.57 & 0.018 & - & - & - \\
\hline
\end{tabular}

${ }^{1}$ Diet CTRL = typical low NDF texturised starter; MFIB = moderate fibre texturised; MFIBNM = moderate fibre, no liquid molasses texturised; HFPEL = high fibre pelleted starter.

${ }^{2}$ MF = MFIB vs CTRL; MOL = MFIBNM vs MFIB; HFP = HFPEL vs CTRL. 
(MFIB vs CTRL; $P \geq 0.42$ ) or its interaction with phase $(P \geq 0.30)$. Moreover, weekly means of starter DMI (Figure 1 ) suggested no divergence in intakes between diets CTRL and MFIB at any time during the trial. Collectively, these data indicated that adding NFFS to modestly increase dietary NDF content (from 16.1 to $20.2 \%$ of DM) resulted in no compromise in overall performance of calves.

Removing liquid molasses and further increasing dietary NFFS content (MFIBNM vs MFIB) tended to increase $(P=0.07)$ final BW and increased $(P=0.05) \mathrm{BW}$ gain. These effects were consistent across pre- and post-weaning phases (interaction with phase; $P \geq 0.22$ ). There was no main effect or interaction of molasses with phase $(P \geq 0.35)$ on starter DMI. However, there was an interaction $(P<0.001)$ between diet and week for starter DMI based on inspection of weekly mean intakes (Figure 1), it appeared that this may have partially been due to the effects of molasses level. As such, a specific contrast was constructed to test the differences between diets MFIB and MFIBNM in average intakes pooled at weeks four through to six, which revealed that intakes were higher $(P=0.006)$ with reduced molasses levels during this time. Both starter intakes and BW gains were reduced when either 7\% (Lesmeister and Heinrichs, 2005) or 5\% (Hill et al., 2008a) molasses was added to a basal diet that contained 5\% molasses. Finally, Oltramari et al. (2016) reported no differences among starter feeds containing 0, 5, or $10 \%$ molasses on starter intake or weight gain in nursing calves. Collectively, these data suggested no benefit with increasing molasses levels beyond 5\% of DM and supported the questioning of the utility of molasses inclusion in calf starters (Hill et al., 2008a) beyond perhaps some minimal amount to help control dustiness or fines.
Compared to diet CTRL, diet HFPEL was associated with a numerical increase in final BW, gain and ADG in the preweaning phase, but showed a numerical decrease in these responses in the post-weaning phase (HFPEL vs CTRL $\times$ Phase, $P \leq 0.022)$. This same pattern tended to occur for daily starter DMI $(P=0.068)$ and was observed for total starter DMI $(P=0.0022)$. Finally, feed efficiency was decreased $(P=0.018)$ by diet HFPEL. Examining weekly means (Figure 1) revealed that starter DMI for this diet was numerically the highest at weaning (i.e. week seven) but the rate of increase slowed thereafter and this diet had the numerically lowest DMI for weeks nine and 10. It was noted that several calves on the HFPEL diet showed signs of bloat beginning in week nine, and it is likely that this diet failed to provide adequate abrasiveness (Greenwood et al., 1997) to maintain gut health as calves progressed into the post-weaning phase.

Evaluating the responses of weight gain and intake to NFFS inclusion in starter feeds reported in the literature is complex due to the multitude of factors involved in experimental comparisons including: (1) widely varying inclusion levels; (2) the physical form of experimental diets may be pelleted, texturised, mash, or change (i.e. be confounded with) with NFFS addition; (3) data come from a wide variety (e.g. cottonseed hulls, soyhulls, distillers grains, or blends) of NFFS; (4) forage may be blended in the starter, offered separately, or not at all; and (5) data may be available for only either the pre- or post-weaning phases, or sometimes both. To facilitate this evaluation, data was extracted from the publications that had been identified as pertinent to the discussion of the current results, where various levels of NFFS were fed in both pre- and post-

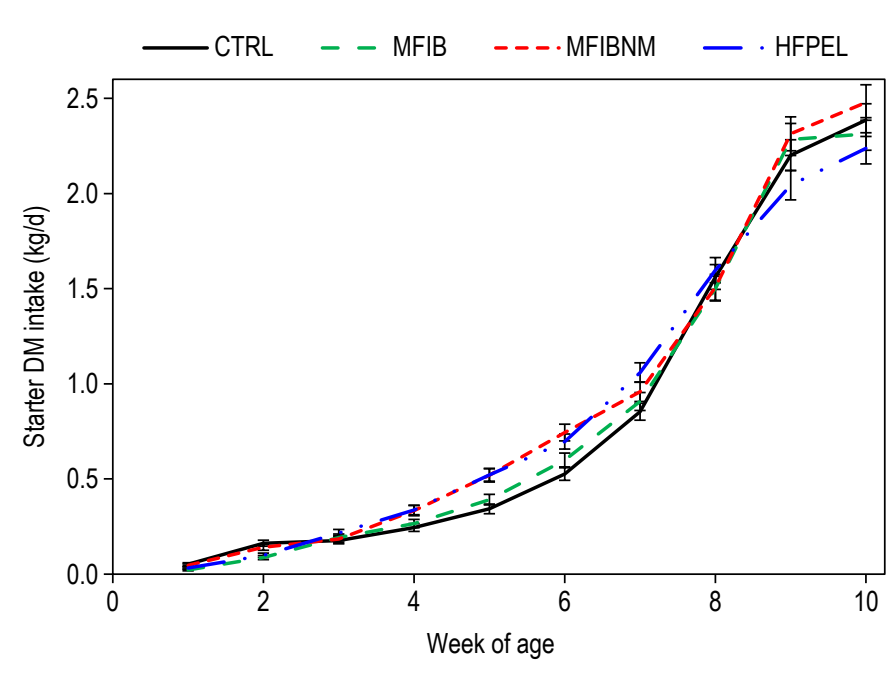

Figure 1. Least square means ( \pm SEM) of starter dry matter (DM) intake in Holstein calves fed a control texturised diet (CTRL), a moderate fibre starch texturised diet (MFIB), a moderate fibre texturised diet with no liquid molasses (MFIBNM), or a pelleted high fibre diet (HFPEL). 
weaning phases (Dennis et al., 2017; Hill et al., 2008a,b; Fokkink et al., 2011; Porter et al., 2007; Suarez-Mena et al., 2011 studies 1 and 3; Terre et al., 2013). When only some of the diets in the experiments included forage (i.e. one diet from Hill et al., 2008b and two diets from Terre et al., 2013), these were excluded to remove confounding factors. All the diets in the post-weaning phase (from Dennis et al., 2017) contained forage, therefore these were retained in the data set. These data were combined with data from the present study such that the data set contained forty-eight observations from nine different studies.

Data from the present study fitted well with previously published data and the data set indicated a large effect of the trial protocol and suggested a negative effect of NDF on intake and ADG (Figure 2A and 2B) and a strong relationship between ADG and intake (Figure $2 \mathrm{C}$ and 2D).

Therefore, the effects of NDF content on starter intake and the effects of both NDF content and starter intake on ADG were evaluated using linear mixed modelling, implemented with the linear mixed effects regression function of the LME4 package (R Core Team, 2019). The effect of each individual study typically is large in animal agriculture experiments (St-Pierre, 2001) and this, in fact, is what necessitates the use of mixed modelling, as opposed to regression, in evaluating data across studies. Thus, for ADG and starter intake for both pre- and post-weaning phases, the initial model constructed consisted simply of the random effect (intercept) of study. Each time subsequent terms were added to the model, they were evaluated for significance based on a likelihood ratio test relative to the previous model (Zuur, 2009). Additional terms evaluated for starter intake were both fixed and random effects (slopes) of diet NDF content. For modelling ADG, both fixed and random effects (slopes) for NDF content and starter intake and also the interaction of NDF content with starter intake were evaluated.

The slope of the relationship between starter intake $(\mathrm{kg} / \mathrm{d})$ and NDF (as \% of DM) was negative for both pre-weaning $(-0.00107)$ and post-weaning $(-0.00362)$ phases but failed to reach significance in either case $(P \geq 0.27)$. For ADG, significant negative $(P \leq 0.05)$ and positive $(P<0.001)$ relationships were obtained for NDF content and starter intake, respectively. Neither the effect of random slopes for NDF content or starter intake nor the interaction between
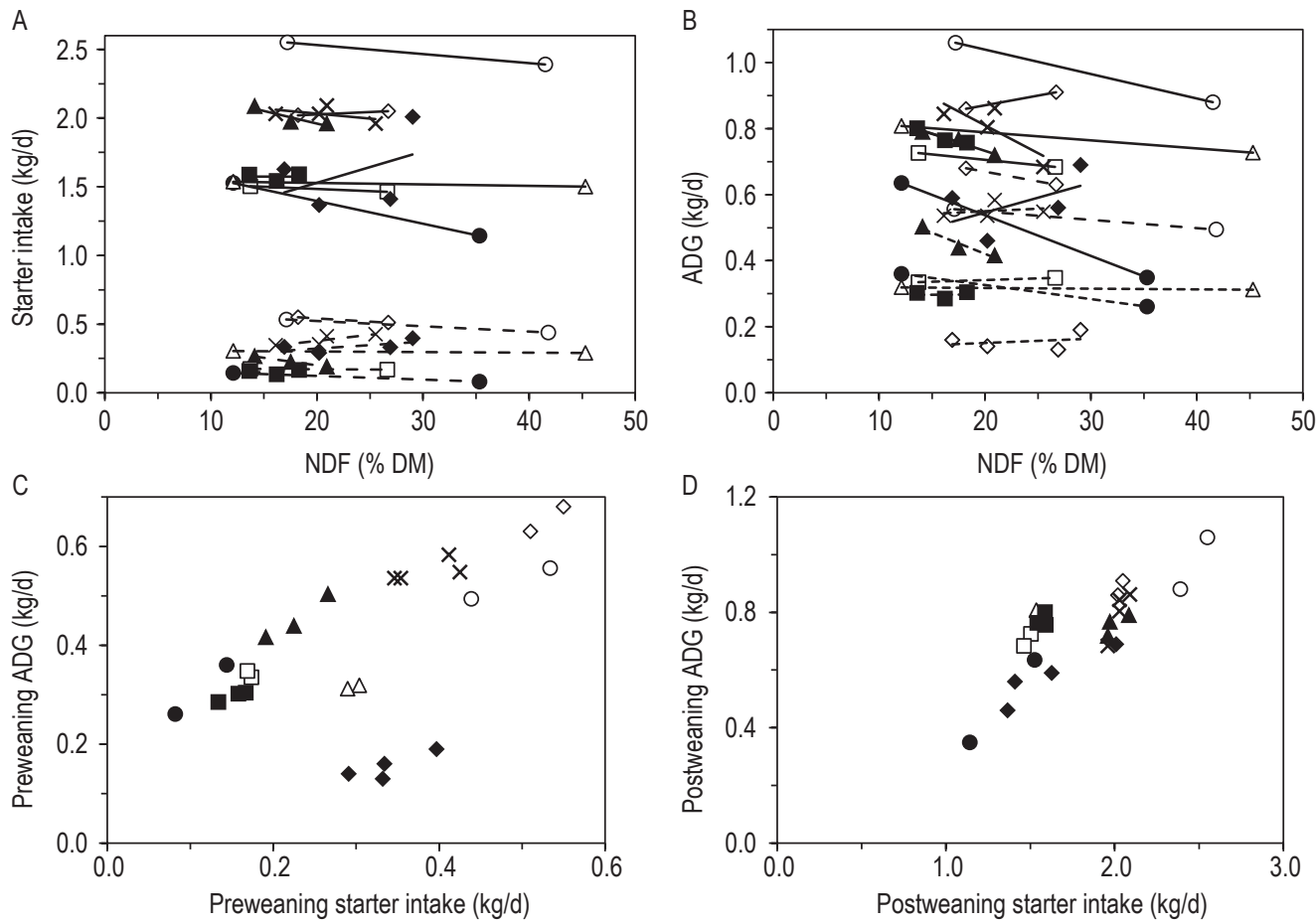

Figure 2. Data set used for linear mixed modelling analysis. Panels A and B display the relationship between preweaning (dashed line) and postweaning (solid line) starter intake or average daily gain (ADG) with starter neutral detergent fibre (NDF) content. Panels $C$ and D display the relationship between ADG and starter intake for preweaning and postweaning phases. Legend: Dennis et al., 2017 $(\circ)$, Fokkink et al., $2011(\bullet)$, Hill et al., 2008a trial $2(\Delta)$, Hill et al., 2008b trial $3(\Delta)$, Suarez-Mena et al., 2011 trial 1 ( $\square)$, Suarez-Mena et al., 2011 trial $3(\square)$, Terre et al., $2013(())$, Porter et al., $2007(\diamond)$, present study $(X)$. DM = dry matter. 
starter intake and NDF content were significant $(P \geq 0.36)$. Thus, the final models for ADG were as follows:

Preweaning ADG $(\mathrm{kg} / \mathrm{d})=$ $0.219+0.664 \times($ starter intake, $\mathrm{kg} / \mathrm{d})-0.000818 \times(\mathrm{NDF}, \% \mathrm{DM})$; Root mean square error $($ RMSE $)=0.0131$

Postweaning ADG $(\mathrm{kg} / \mathrm{d})=$ $0.159+0.373 \times($ starter intake, $\mathrm{kg} / \mathrm{d})-0.00346 \times(\mathrm{NDF}, \% \mathrm{DM})$; RMSE $=0.0308$.

Finally, inspection of residuals for each model fit revealed no bias due to study (i.e. there were residuals both greater than and less than zero for each study in each model). Overall, excellent agreement between observed and predicted ADG was evident for both pre- and post-weaning phases (Figure 3). Again, it was important to recall that the predicted values in Figure 3 incorporated variation due to the individual study (random) effect as well as fixed effects of interest (i.e. NDF content and starter intake).

Several conclusions may be drawn regarding the incorporation of NFFS in calf starters from this analysis. Firstly, data from the present study fitted well with previously published data. Secondly, the data set evaluated included a wide array of factors, including source and level of NFFS, presence or absence of forage, and physical form, which included aspects of confounding (i.e. physical form was confounded with NFFS addition in Fokkink et al., 2011; Dennis et al., 2017, and the present study), and yet was well described, based on RMSE and inspection of Figure 3, by relatively simple models. Thirdly, the fact that random slopes for NDF content as well as starter intake were not significant meant that the effects of NFFS on calf performance from these studies could be considered collectively. That is, across factors which varied in these studies (i.e. source and level of NFFS, presence or absence of forage, and physical form), the effects of NDF and starter intake on ADG did not differ. Fourthly, based on the slopes of fitted models, starter intake was quantitatively much more important than NDF content in its effect on ADG. Moreover, the proportion of variation in ADG explained by NDF content and starter intake, computed from marginal coefficient of determination $\left(\mathrm{R}^{2}\right)$ values (Nakagawa and Schielzeth, 2013), were $0.4 \%$ and $35 \%$ for pre-weaning and 9.7 and $65.7 \%$ for post-weaning phases, respectively.

It may be that successful inclusion of NFFS in calf starters is governed largely by the ability to maintain intake. This would explain why instances where NFFS inclusion did not decrease intake, it caused no decrease in ADG (Porter et al., 2007; Quigley et al., 2018; Suarez-Mena et al., 2011). This reconciled the divergent results obtained in two studies employing nearly identical starter formulas and experimental procedures; Dennis et al. (2017) observed a decreased ADG and starter intake due to NFFS inclusion, while Quigley et al. (2018) observed no effect on ADG (and likewise saw no impact on starter intakes). Finally, the highly significant positive slopes relating ADG to intake were consistent with the idea that the effect of NFFS on ADG was mediated through intake, although such correlation does not necessarily imply causation. The question remains as to what factors contribute to the effect of NFFS on starter intake. Clearly gross problems such as excessive fines in feed (Bateman et al., 2009) or rumen dysfunction (e.g. bloat observed in the postweaning phase for diet HFPEL of the current study) due to NFFS have been documented as having negative effects on intake.
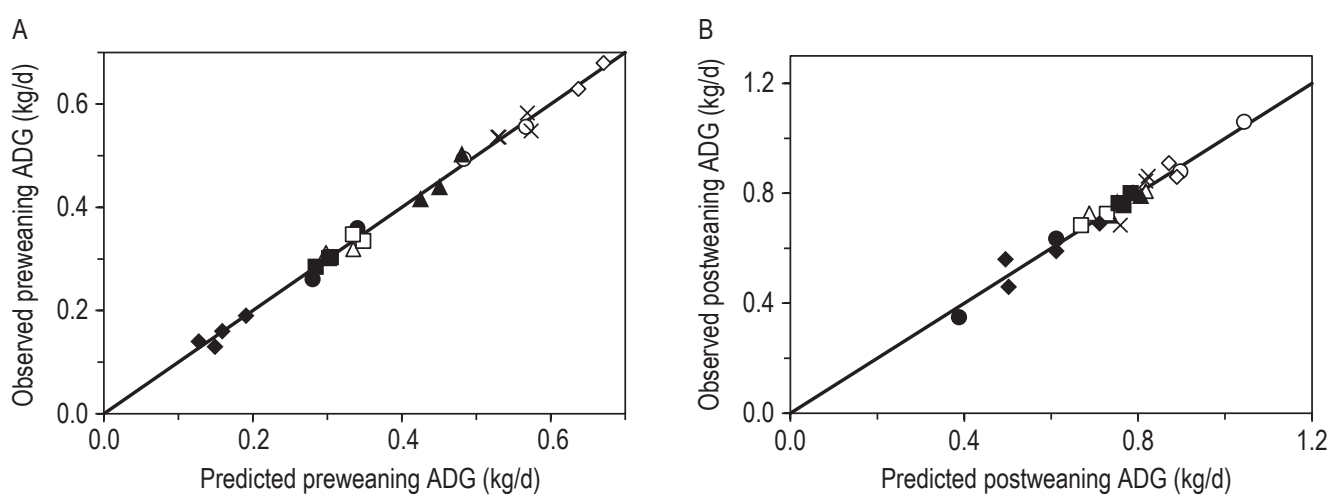

Figure 3. Results of linear mixed modelling analysis showing the relationship between predicted and observed average daily gain (ADG) for preweaning (A) and postweaning (phases) from nine studies. Preweaning ADG $=0.219+0.664 \times(\mathrm{kg} / \mathrm{d}$ starter intake) $0.000818 \times(\%$ neutral detergent fibre (NDF)); RMSE $=0.0131$. Postweaning ADG $=0.159+0.373 \times(\mathrm{kg} / \mathrm{d}$ starter intake) $-0.00346 \times(\%$ NDF); RMSE = 0.0308. Legend: Dennis et al., 2017 (○), Fokkink et al., 2011 (•), Hill et al., 2008a trial 2 ( $\triangle$ ), Hill et al., 2008b trial $3(\Delta)$, Suarez-Mena et al., 2011 trial 1 ( $\square$ ), Suarez-Mena et al., 2011 trial $3(\square)$, Terre et al., $2013(\diamond)$, Porter et al., $2007(\diamond)$, present study (X). 
Total tract apparent NDFD (Figure 4) increased with age $(P<0.001)$ but was not affected by any dietary contrast of interest or by an interaction between diet and week of age $(P \geq 0.11)$. Applying simple linear regression to the diet means $\left(R^{2}=0.95, P<0.001\right)$ indicated that variation in NDFD was well explained simply by a linear increase in calf age. In a meta-regression analysis on the effects of dietary starch concentration for growing calves, $\mathrm{Hu}$ et al. (2018) reported total tract apparent NDFD to range from 56-71\% as well as a negative relationship between dietary starch and NDFD, although this did not reach statistical significance. There is a well-known associative effect in adult cattle, whereby increasing starch content negatively affects NDFD (Firkins, 1997). Reports of decreased NDFD in young calves with increased starch content of starter feed (Hill et al., 2016; Quigley et al., 2018) presumably reflect a similar phenomenon. The range in dietary starch concentration in the present study was (by design) relatively small, and did not appear to have an impact on NDFD. In some innovative work, Quigley (2019a,b) compiled data from several studies and demonstrated that NDFD was well described as a function of cumulative nutrient intake and improved in pelleted vs texturised diets. Taken collectively, the current data demonstrated the steady development of the capacity for fibre digestion with age and indicated that young calves have the capacity for extensive digestion of NDFD. In addition to cumulative nutrient intake, there probably are other important management factors in the development of rumen fibre digestion that are not fully understood, but remain important sources of variation.

Blood glucose concentrations (Figure 5) were affected by both diet and week $(P \leq 0.05)$ and had a tendency for an interaction between diet and week $(P=0.10)$. Moderately increasing NFFS reduced blood glucose concentrations in the pre-weaning, but not post-weaning phase (MFIB vs CTRL $\times$ Phase, $P=0.017$ ), perhaps reflecting the relatively greater advantage of starch over fibre for glucose supply in preruminants compared with functional ruminants.

Blood glucose concentrations were increased by replacing molasses with NFFS (MFIBNM vs MFIB; $P=0.035$ ), which may be, at least partially, explained by the aforementioned differences in starter intake observed for weeks four to six among these two diets. The reduced blood glucose due to the complete pelleted high fibre diet (HFPEL vs CTRL; $P=0.015$ ) suggested that the treatments exceeded the level of NFFS inclusion able to maintain blood glucose concentrations. Post-hoc single df contrasts revealed that, averaged across all diets, blood glucose concentrations were lower $(P<0.001)$ in the post-weaning (i.e. weeks eight and 10) vs preweaning phase (i.e. weeks four and six) and increased with time within both the preweaning (week six vs week four, $P=0.0046$ ) and post-weaning (week $10 \mathrm{vs}$ week eight, $P=0.0028)$ phases. Decreasing blood glucose concentrations with increasing age has been a consistent observation (Khan et al., 2007, 2011; Quigley et al., 1991), and probably reflects the transition from intestinal glucose absorption to hepatic gluconeogenesis associated with the development and transition towards becoming functional ruminants. Others have observed no differences in blood glucose of young calves due to moderate inclusions of NFFS (Laarman et al., 2012; Terre et al., 2013) or the provision of forage (Khan et al., 2011; Terre et al., 2013), while differences among cereal grains have been reported (Khan et al., 2007). Broadly speaking, the current results were consistent with previous reports and illustrated that

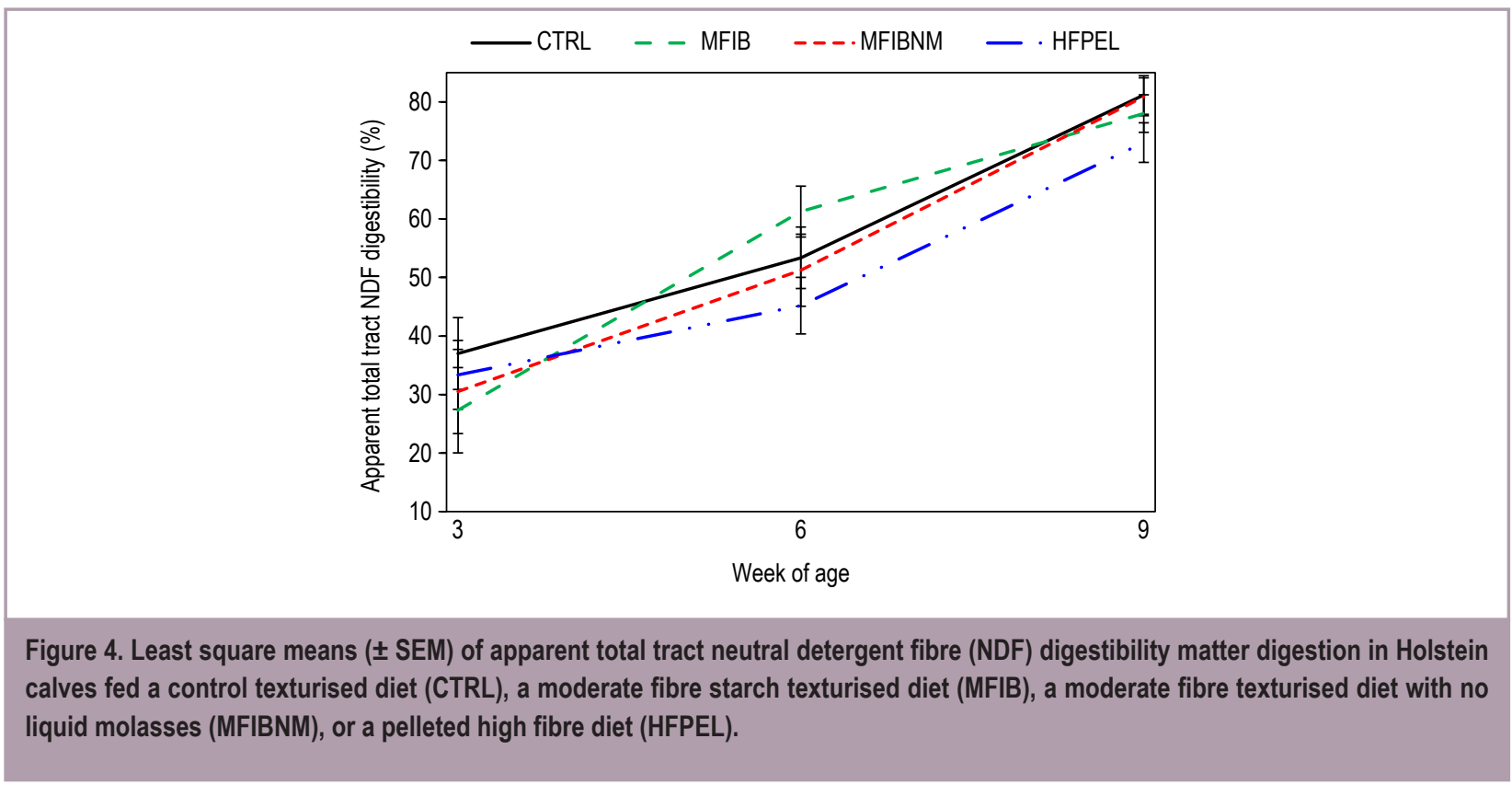




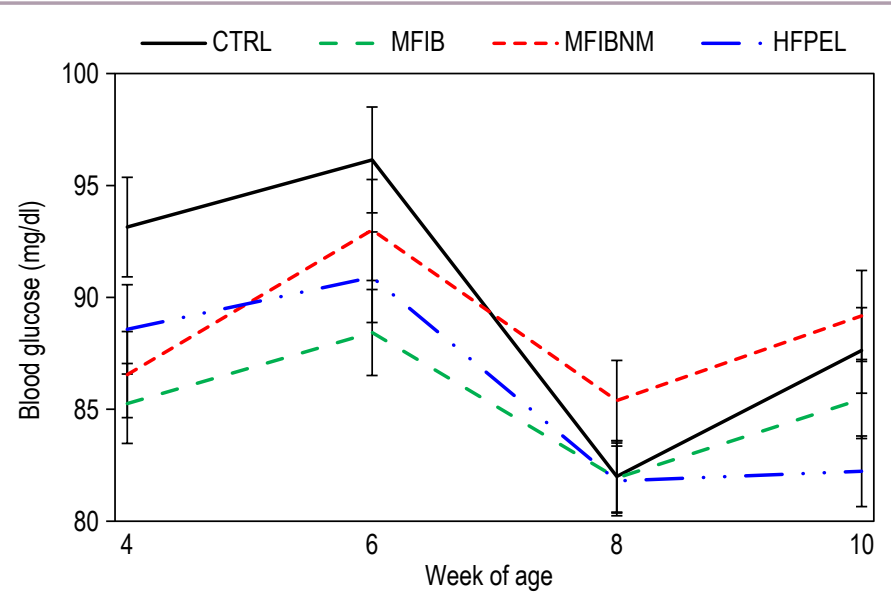

Figure 5. Least square means ( \pm SEM) of blood glucose concentrations in Holstein calves fed a control texturised diet (CTRL), a moderate fibre starch texturised diet (MFIB), a moderate fibre texturised diet with no liquid molasses (MFIBNM), or a pelleted high fibre diet (HFPEL).

the moderate replacement of cereal grains or molasses with NFFS is able to maintain blood glucose concentrations.

As described earlier, censored means for blood BHB concentrations (Figure 6) were evaluated within each sampling time. Concentrations tended to increase $(P=0.07)$ and increased $(P=0.02)$ in calves fed the MFIB diet vs CTRL diet at four and six weeks of age, respectively. The reason for these differences was not clear, as there were no differences in DMI or ruminal NDFD between these diets. Results of a paired t-test of treatment means for week four vs week six data $(P=0.17)$ revealed that $\mathrm{BHB}$ concentrations did not change due to time in the pre-weaning phase. Simple linear regression of treatment means over weeks six to
10 revealed a strong linear trend $\left(R^{2}=0.92, P<0.001\right)$ as calves moved into and through the post-weaning phase. Applying simple linear regression to blood BHB vs ruminal butyrate concentrations from the data of Khan et al. (2008) obtained from starter feeds based on four different cereal grains collected from calves ranging from 35 to $70 \mathrm{~d}$ of age, revealed a strong positive linear trend $\left(R^{2}=0.73\right.$, $P<0.001)$. This was consistent with the idea that blood BHB concentrations in young calves can serve as a useful indicator of the establishment of both rumen microbial fermentation and the ketogenic functionality of rumen epithelial tissue (Baldwin et al., 2004).

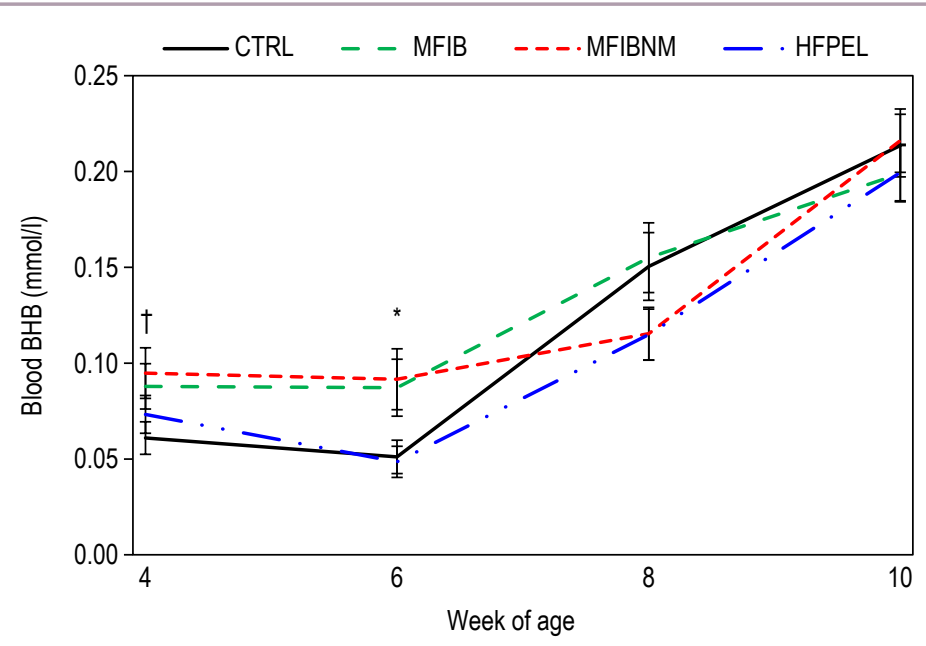

Figure 6. Censored least square means ( \pm SEM) of blood beta-hydroxybutyrate concentrations in Holstein calves fed a control texturised diet (CTRL), a moderate fibre starch texturised diet (MFIB), a moderate fibre texturised diet with no liquid molasses (MFIBNM), or a pelleted high fibre diet (HFPEL). For each time point, symbols denote CTRL vs MFIB, $P=0.07$ (†) or $P=0.02(*)$. 
Several authors have observed excellent agreement between blood BHB concentrations and starter intake in calves (Chapman et al., 2017; Deelen et al., 2016; Quigley et al., 1991) and Deelen et al. (2016) suggested its applicability to indicate readiness for weaning. They determined, based on specificity and sensitivity, an optimal cut-point of $0.1 \mathrm{mmol} / \mathrm{l}$ blood BHB to indicate a $1 \mathrm{~kg} / \mathrm{d}$ starter intake which has been suggested as appropriate for weaning (Drackley, 2008). A plot of blood BHB concentrations vs starter DMI from the current data (Figure 7) suggested that concentrations did not increase until a threshold level of starter DMI was obtained and then increased linearly thereafter. Fitting these data to a piecewise linear regression model using the segmented package resulted in an initial slope $(-0.075)$ that was not different from zero $(P=0.76)$. Thus, data were re-fitted with the initial slope constrained to zero, which produced an excellent fit (model RMSE $=0.017$ ), with an intercept of $0.074 \mathrm{mmol} / \mathrm{l}$, a change point of $0.762 \mathrm{~kg} \mathrm{DMI}$, and a slope of 0.082. From this model, the starter DMI that corresponded to blood BHB concentrations of $0.1 \mathrm{mmol} /$ was determined to be $1.08 \mathrm{~kg} / \mathrm{d}$, confirming the results of Deelen et al. (2016).

Importantly, each of the above studies employed laboratorybased methods for BHB analyses when its relationship with either ruminal butyrate or starter intake was established. However, practical application of these relationships would be greatly enhanced by the ability to use hand-held meters to make calf-side determinations. Because blood $\mathrm{BHB}$ concentrations in young calves are often below the limit of detection of handheld meters, it is inevitable that application of this technology will result in censored data.
Options available for dealing with nondetects (Helsel, 2012) include: (1) substitution of some value (e.g. 0) below the limit of detection; (2) deletion of the observations; (3) nonparametric methods using contingency tables; (4) nonparametric survival analysis; and (5) MLE. The current trial employed MLE, as described previously, because it yielded the maximal amount of information among these approaches, including the ability to generate parameter estimates (e.g. means and SE) and conduct hypothesis tests. One limitation of the MLE methodology was that, in practice, adequate parameter estimation requires approximately 25-50 observations (Helsel, 2012), restricting its application to groups of calves rather than individual measurements. Thus, it would be best suited to implementation on larger farms as a routine quality assurance measure or to evaluate the impact of management changes.

Challenges associated with censored data may explain some previously reported issues with calf-side BHB testing. Deelen et al. (2016) demonstrated excellent agreement between laboratory-based and calf-side blood BHB measurements and, yet, inexplicably reported an optimal cut-point of $0.2 \mathrm{mmol} / \mathrm{l}$ with the hand-held meter vs the $0.1 \mathrm{mmol} / \mathrm{l}$ determined for laboratory-base measurements. This data set would have had a large number of nondetects for the calf-side measurements (the limit of detection of the Precision Xtra employed in that study was $0.1 \mathrm{mmol} / \mathrm{l}$ ) and yet it appears that they applied their measurements to single blood samples. Suarez-Mena et al. (2017) obtained a significant $(P<0.02)$ but unsatisfactory $\left(R^{2}=0.28\right)$ relationship between blood $\mathrm{BHB}$ concentrations measured

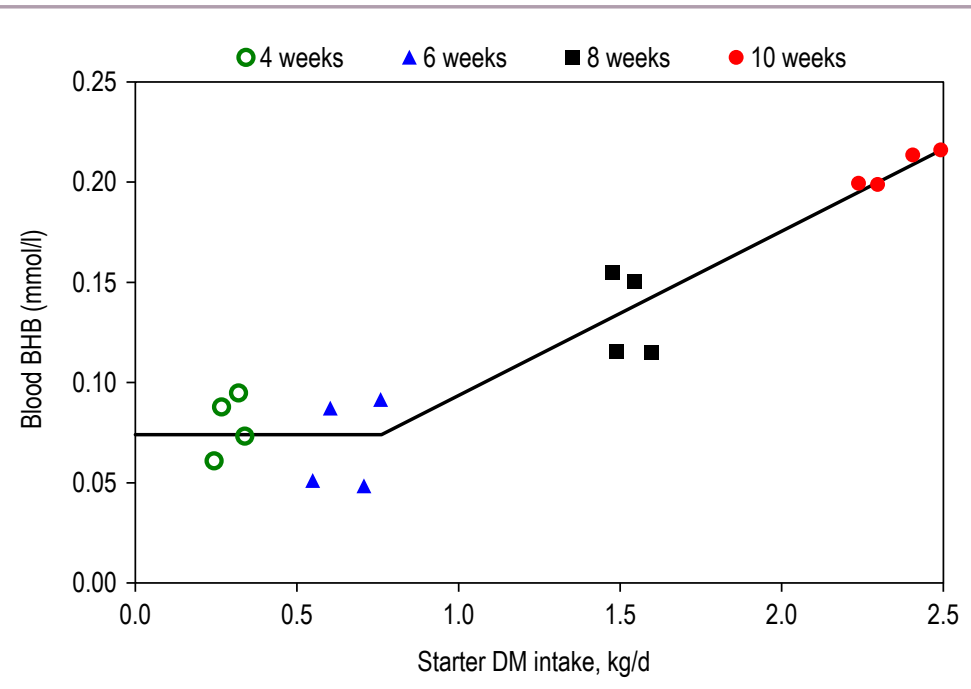

Figure 7. Weekly diet censored diet mean blood $\beta$-hydroxybutyrate (BHB) concentrations versus starter dry matter (DM) intakes. The line is a fitted piecewise linear regression model with the initial slope constrained to zero. Intercept $=0.074$, change point $=0.762$, and slope $=0.082$ (model RMSE $=0.017$ ). 
with the Nova Max Plus system (the same as employed in the present study) and starter intake in calves up to seven weeks of age. Likewise, the authors evaluated this relationship based on either single measurements or the mean of triplicates of blood BHB and obtained a heavily censored data set. In summary, the relationship between starter intake and blood BHB measurements appeared well established (Chapman et al., 2017; Deelen et al., 2016; Quigley et al., 1991); however, the challenges in its practical application involve appropriately handling the censored data obtained. Importantly, an illustration of the use of Microsoft Excel for MLE computations is available (Flynn, 2009), thus making this approach readily accessible.

\section{Conclusions}

Moderately increasing the NDF content of textured starter feed by substituting NFFS for cereal grains and/or molasses had no negative effects on intake, weight gain or indicators of the development of ruminal function (i.e. blood BHB concentrations or NDFD). Further increasing NFFS content in the form of a completely pelleted starter feed reduced calf performance post-weaning, probably due to a lack of physically effective fibre to stimulate ruminal development. A quantitative review of previously published literature, along with the data from the present study, suggested that maintaining intake may be the key to successful utilisation of NFFS in calf starters. With careful application and proper computations, calf-side blood BHB concentrations appear useful as an indicator of starter intake and readiness for weaning.

\section{Acknowledgements}

The authors acknowledge that this research was partially funded by Cargill Animal Nutrition.

\section{Conflict of interest}

M.A. Messman is an employee of Cargill Animal Nutrition.

\section{References}

AOAC. 1990. Official Methods of Analysis. 15 ${ }^{\text {th }}$ ed. Association of Official Analytical Chemistry, Arlington, VA, USA.

Baldwin, R.L., McLeod, K.R., Klotz, J.L. and Heitmann, R.N., 2004. Rumen development, intestinal growth and hepatic metabolism in the pre- and postweaning ruminant. Journal of Dairy Science 87: E55-E65. https://doi.org/10.3168/jds.S0022-0302(04)70061-2

Bateman, H.G., Hill, T.M., Aldrich, J.M. and Schlotterbeck, R.L., 2009. Effects of corn processing, particle size, and diet form on performance of calves in bedded pens. Journal of Dairy Science 92: 782-789. https://doi.org/10.3168/jds.2008-1242

Bergman, E.N. 1990. Energy contributions of volatile fatty acids from the gastrointestinal tract in various species. Physiological Reviews 70: 567-590. https://doi.org/10.1152/physrev.1990.70.2.567
Chapman, C.E., Hill, T.M., Elder, D.R. and Erickson, P.S., 2017. Nitrogen utilisation, preweaning nutrient digestibility, and growth effects of Holstein dairy calves fed 2 amounts of a moderately high protein or conventional milk replacer. Journal of Dairy Science 100: 279-292. https://doi.org/10.3168/jds.2016-11886

Deelen, S.M., Leslie, K.E., Steele, M.A., Eckert, E., Brown, H.E. and DeVries, T.J., 2016. Validation of a calf-side $\beta$-hydroxybutyrate test and its utility for estimation of starter intake in dairy calves around weaning. Journal of Dairy Science 99: 7624-7633. https:// doi.org/10.3168/jds.2016-11097

Dennis, T.S., Suarez-Mena, F.X., Hill, T.M., Quigley, J.D. and Schlotterbeck, R.L., 2017. Effects of egg yolk inclusion, milk replacer feeding rate, and low-starch (pelleted) or high-starch (texturised) starter on Holstein calf performance through 4 months of age. Journal of Dairy Science 100: 8995-9006. https://doi.org/10.3168/ jds.2017-13169

Drackley, J.K. 2008. Calf nutrition from birth to breeding. Veterinary Clinics of North America. Food Animal Practice 24: 55-86. https:// doi.org/10.1016/j.cvfa.2008.01.001

Firkins, J.L. 1997. Effects of feeding non-forage fiber sources on site of fiber digestion. Journal of Dairy Science 80: 1426-1437. https:// doi.org/10.3168/jds.S0022-0302(97)76072-7

Flynn, M.R. 2009. Analysis of censored exposure data by constrained maximisation of the Shapiro-Wilk W statistic. Annals of Occupational Hygiene 54: 263-271. https://doi.org/10.1093/annhyg/ mep083

Fokkink, W., Hill, T., Bateman, H., Aldrich, J.M., Schlotterbeck, R. and Kertz, A., 2011. Case study: effect of high-and low-cerealgrain starters on straw intake and rumen development of neonatal Holstein calves. Professional Animal Scientist 27: 357-364.

Gilbert, R.O. 1987. Statistical methods for environmental pollution monitoring. Van Nostrand Reinhold Co, New York, NY, USA.

Greenwood, R.H., Morill, J.L., Titgemeyer, E.C. and Kennedy, G.A., 1997. A new method of measuring diet abrasion and its effect on the development of the forestomach. Journal of Dairy Science 80: 2534-2541. https://doi.org/10.3168/jds.S0022-0302(97)76207-6

Helsel, D.R. 2012. Statistics for censored environmental data using Minitab and R. $2^{\text {nd }} \mathrm{ed}$. Wiley series in statistics in practice. Wiley, Hoboken, NJ, USA.

Hill, T.M., Bateman, H.G., Aldrich, J.M. and Schlotterbeck, R.L., 2008a. Effects of feeding different carbohydrate sources and amounts to young calves. Journal of Dairy Science 91: 3128-3137. https://doi. org/10.3168/jds.2007-0950

Hill, T.M., Bateman, H.G., Aldrich, J.M. and Schlotterbeck, R.L., 2008b. Effects of the amount of chopped hay or cottonseed hulls in a textured calf starter on young calf performance. Journal of Dairy Science 91: 2684-2693. https://doi.org/10.3168/jds.2007-0935

Hill, T.M., Bateman, H.G., Aldrich, J.M. and Schlotterbeck, R.L., 2012. High-starch, coarse-grain, low-fiber diets maximize growth of weaned dairy calves less than 4 months of age. Professional Animal Scientist 28: 325-331. https://doi.org/10.15232/S10807446(15)30363-6 
Hill, T.M., Bateman, H.G., Quigley, J.D., Aldrich, J.M., Schlotterbeck, R.L. and Heinrichs, A.J., 2013. Review: New information on the protein requirements and diet formulation for dairy calves and heifers since the Dairy NRC 2001. Professional Animal Scientist 29: 199-207. https://doi.org/10.15232/S1080-7446(15)30225-4

Hill, T.M., Quigley, J.D., Bateman, H.G., Aldrich, J.M. and Schlotterbeck, R.L., 2016. Source of carbohydrate and metabolizable lysine and methionine in the diet of recently weaned dairy calves on digestion and growth. Journal of Dairy Science 99: 2788-2796. https://doi. org/10.3168/jds.2015-10571

Hu, W., Hill, T.M., Dennis, T.S., Suarez-Mena, F.X., Quigley, J.D., Knapp, J.R. and Schlotterbeck, R.L., 2018. Relationships between starch concentration of dry feed, diet digestibility, and growth of dairy calves up to 16 weeks of age. Journal of Dairy Science 101: 7073-7081. https://doi.org/10.3168/jds.2018-14583

Khan, M.A., Bach, A., Weary, D.M. and von Keyserlingk, M.A. G., 2016. Invited review: transitioning from milk to solid feed in dairy heifers. Journal of Dairy Science 99: 885-902. https://doi.org/10.3168/ jds.2015-9975

Khan, M.A., Lee, H.J., Lee, W.S., Kim, H.S., Kim, S.B., Ki, K.S., Park, S.J., Ha, J.K. and Choi, Y.J. 2007. Starch source evaluation in calf starter: I. Feed consumption, body weight gain, structural growth, and blood metabolites in Holstein calves. Journal of Dairy Science 90: 5259-5268. https://doi.org/10.3168/jds.2007-0338

Khan, M.A., Lee, W.S., Kim, H.S., Kim, S.B., Park, S.B., Baek, K.S., Ha, J.K. and Choi, Y.J., 2008. Starch source evaluation in calf starter: II. Ruminal parameters, rumen development, nutrient digestibilities, and nitrogen utilisation in Holstein calves. Journal of Dairy Science 91: 1140-1149. https://doi.org/10.3168/jds.2007-0337

Khan, M.A., Weary, D.M. and von Keyserlingk, M.A.G., 2011. Hay intake improves performance and rumen development of calves fed higher quantities of milk. Journal of Dairy Science 94: 3547-3553. https://doi.org/10.3168/jds.2010-3871

Laarman, A.H., Sugino, T. and Oba, M., 2012. Effects of starch content of calf starter on growth and rumen $\mathrm{pH}$ in Holstein calves during the weaning transition. Journal of Dairy Science 95: 4478-4487. https://doi.org/10.3168/jds.2011-4822

Lesmeister, K.E. and Heinrichs, A.J., 2005. Effects of adding extra molasses to a texturised calf starter on rumen development, growth characteristics, and blood parameters in neonatal dairy calves. Journal of Dairy Science 88: 411-418.

Martel, C.A., Titgemeyer, E.C., Mamedova, L.K. and Bradford, B.J., 2011. Dietary molasses increases ruminal $\mathrm{pH}$ and enhances ruminal biohydrogenation during milk fat depression. Journal of Dairy Science 94: 3995-4004. https://doi.org/10.3168/jds.2011-4178

Nakagawa, S. and Schielzeth, H., 2013. A general and simple method for obtaining R2 from generalized linear mixed-effects models. Methods in Ecology and Evolution 4: 133-142. https://doi.org/10.1111/j.2041210x.2012.00261.x

National Research Council (NRC), 2001. Nutrient requirements of dairy cattle. $7^{\text {th }}$ rev. ed. National Academy Press, Washington D.C., USA.
Oltramari, C.E., Nápoles, C.G.O., De Paula, M.R., Silva, J.T., Gallo, M.P.C., Pasetti, M.H.O. and Bittar, C.M.M., 2016. Performance and metabolism of calves fed starter feed containing sugarcane molasses or glucose syrup as a replacement for corn. Asian-Australas. Journal of Animal Science 29: 971-978. https://doi.org/10.5713/ajas.15.0550

Pinheiro, J.C. and Bates, D., 2000. Mixed effects models in S and -Plus. Springer-Verlag, New York, NY, USA.

Porter, J.C., Warner, R.G. and Kertz, A.F., 2007. Effect of fiber level and physical form of starter on growth and development of dairy calves fed no forage. Professional Animal Scientist 23: 395-400.

Quigley, J.D., Caldwell, L.A., Sinks, G.D. and Heitmann, R.N., 1991. Changes in blood glucose, nonesterified fatty acids, and ketones in response to weaning and feed intake in young calves. Journal of Dairy Science 74: 250-257. https://doi.org/10.3168/jds.S00220302(91)78167-8

Quigley, J.D., Hill, T.M., Dennis, T.S., Suarez-Mena, F.X. and Schlotterbeck, R.L., 2018. Effects of feeding milk replacer at 2 rates with pelleted, low-starch or texturised, high-starch starters on calf performance and digestion. Journal of Dairy Science 101: 5937-5948. https://doi.org/10.3168/jds.2017-13851

Quigley, J.D., Hu, W., Knapp, J.R., Dennis, T.S. and Suarez-Mena, F.X., 2019a. Estimates of calf starter energy affected by consumption of nutrients. 1. Evaluation of models to predict changing digestion on energy content in calf starters. Journal of Dairy Science 102: 2232-2241. https://doi.org/10.3168/jds.2018-15353

Quigley, J.D., Hu, W., Knapp, J.R., Dennis, T.S., Suarez-Mena, F.X. and Hill, T.M., 2019b. Estimates of calf starter energy affected by consumption of nutrients. 2. Effect of changing digestion on energy content in calf starters. Journal of Dairy Science 102: 2242-2253. https://doi.org/10.3168/jds.2018-15354

R Core Team. 2019. R: a language and environment for statistical computing. R Foundation for Statistical Computing, Vienna, Austria.

Sakata, T. and Tamate, H., 1978. Rumen epithelial cell proliferation accelerated by rapid increase in intraruminal butyrate. Journal of Dairy Science 61: 1109-1113. https://doi.org/10.3168/jds.S00220302(78)83694-7

Sakata, T. and Tamate, H., 1979. Rumen epithelium cell proliferation accelerated by propionate and acetate. Journal of Dairy Science 62: 49-52. https://doi.org/10.3168/jds.S0022-0302(79)83200-2

Sander, E.G. Warner, R.G., Harrison, H.N. and Loosli, J.K., 1959. The stimulatory effect of sodium butyrate and sodium propionate on the development of rumen mucosa in the young calf. Journal of Dairy Science 42: 1600-1605. https://doi.org/10.3168/jds.S00220302(59)90772-6

Stobo, I.J.F., Roy, J.H.B. and Gaston, H.J., 1966. Rumen development in the calf: 1 . The effect of diets containing different proportions of concentrates to hay on rumen development. British Journal of Nutrition 20: 171-188. https://doi.org/10.1079/BJN19660021

St-Pierre, N.R. 2001. Invited review: integrating quantitative findings from multiple studies using mixed model methodology1. Journal of Dairy Science 84: 741-755.

Suarez-Mena, F.X., Hill, T.M., Heinrichs, A.J., Bateman, H.G., Aldrich, J.M. and Schlotterbeck, R.L., 2011. Effects of including corn distillers dried grains with solubles in dairy calf feeds. Journal of Dairy Science 94: 3037-3044. https://doi.org/10.3168/jds.2010-3845 
Suarez-Mena, F.X., Hu, W., Dennis, T.S., Hill, T.M. and Schlotterbeck, R.L. 2017., $\beta$-Hydroxybutyrate (BHB) and glucose concentrations in the blood of dairy calves as influenced by age, vaccination stress, weaning, and starter intake including evaluation of BHB and glucose markers of starter intake. Journal of Dairy Science 100: 2614-2624. https://doi.org/10.3168/jds.2016-12181

Terre, M., Pedrals, E., Dalmau, A. and Bach, A., 2013. What do preweaned and weaned calves need in the diet: A high fiber content or a forage source?. Journal of Dairy Science 96: 5217-5225. https:// doi.org/10.3168/jds.2012-6304
Van Keulen, J. and Young, B.A., 1977. Evaluation of acid-insoluble ash as a natural marker in ruminant digestibility studies. Journal of Animal Science 44: 282-287.

Van Soest, P.J., Robertson, J.B. and Lewis, B.A., 1991. Methods for dietary fiber, neutral detergent fiber, and nonstarch polysaccharides in relation to animal nutrition. Journal of Dairy Science 74: 35833597. https://doi.org/10.3168/jds.S0022-0302(91)78551-2

Zuur, A.F., 2009. Mixed effects models and extensions in ecology with R. Statistics for biology and health. Springer, New York, NY, USA. 
